\title{
The impact of COVID-19 pandemic in the quality of sleep by Pittsburgh Sleep Quality Index: A systematic review
}

\author{
O impacto da pandemia COVID-19 na qualidade do sono pelo \\ Índice de Qualidade do Sono de Pittsburgh: uma revisão sistemática
}

\author{
Luiz Felipe Ferreira de Souza (https://orcid.org/0000-0002-4308-2558) 1,2 \\ Laisa Liane Paineiras-Domingos (https://orcid.org/0000-0003-3451-5056) 1,4,5 \\ Maria Eduarda de Souza Melo-Oliveira (https://orcid.org/0000-0003-4420-6898) 1,2 \\ Juliana Pessanha-Freitas (https://orcid.org/0000-0002-6059-0810) ${ }^{1}$ \\ Eloá Moreira-Marconi (https://orcid.org/0000-0002-9029-1328) 1,3 \\ Ana Cristina Rodrigues Lacerda (https://orcid.org/0000-0001-5366-3754) ${ }^{6}$ \\ Vanessa Amaral Mendonça (https://orcid.org/0000-0002-1696-6091) ${ }^{6}$ \\ Danubia da Cunha Sá-Caputo (https://orcid.org/0000-0002-9263-1576) 1,4,5 \\ Mario Bernardo-Filho (https://orcid.org/0000-0002-4718-448X) ${ }^{1}$
}

\footnotetext{
${ }^{1}$ Laboratório de Vibrações Mecânicas e Práticas Integrativas, Departamento de Biofísica e Biometria, Instituto de Biologia Roberto Alcântara Gomes e Policlínica Piquet Carneiro, Universidade do Estado do Rio de Janeiro (UERJ). Av. Marechal Rondon 381, São Francisco Xavier. 20950-003 Rio de Janeiro RJ Brasil. lumadaragu@gmail.com ${ }^{2}$ Programa de PósGraduação em Saúde, Medicina Laboratorial e Tecnologia Forense, UERJ. Rio de Janeiro RJ Brasil.

${ }^{3}$ Programa de PósGraduação em

Fisiopatologia Clínica e Experimental, Faculdade de Ciências, UERJ. Rio de Janeiro RJ Brasil.

${ }^{4}$ Programa de Pós-

Graduação em Ciências Médicas, Faculdade de Ciências Médicas, UERJ. Rio de Janeiro RJ Brasil.

${ }^{5}$ Faculdade Bezerra de Araújo. Rio de Janeiro RJ Brasil.

${ }^{6}$ Centro Integrado de Pós-Graduação e Pesquisa em Saúde, Faculdade de Ciências Biológicas e da Saúde, Universidade Federal dos Vales do Jequitinhonha e Mucuri. Diamantina MG Brasil.
}

\begin{abstract}
This article aims to evaluate the sleep quality in individuals during the COVID-19 pandemic by Pittsburgh Sleep Quality Index (PSQI). Searches were conducted in the PubMed, Embase, Web of Science, and PEDro databases, on May 22, 2020. In the publications, 208 articles were found and, considering the eligibility criteria, 10 articles were included at the end, showing the effects on sleep quality during the pandemic, in populations hospitalized, quarantined, and in frontline health professionals. The PSQI measured sleep disorders and a higher score indicated poor sleep quality. Nine articles were classified with evidence level $I V$ and one as level III-2. Eight studies present a "serious" risk of bias and two in "moderate". The studies investigated different populations and described the results as "poor" sleep quality, considering the PSQI on quarantined individuals and frontline health professionals as the most committed. A poor sleep quality was found in the populations evaluated in the selected publications, probably, due to the COVID-19 to contribute as a risk factor for mental health. Psychological interventions must be made to minimize the consequences through social support and social capital.
\end{abstract}

Key words Sleep, Self-assessment, Social isolation, COVID-19
Resumo O objetivo deste artigo é avaliar a qualidade do sono em indivíduos durante a pandemia de COVID-19 pelo Índice de Qualidade do Sono de Pittsburgh (IQSP). Buscas foram realizadas nas bases de dados PubMed, Embase, Web of Science e PEDro, em 22 de maio de 2020. Nas publicações, foram encontrados 208 artigos $e$, considerando os critérios de elegibilidade, foram incluídos ao final 10 artigos, mostrando os efeitos na qualidade do sono durante a pandemia, em populações hospitalizadas, em quarentena e em profissionais de saúde. O IQSP mediu os distúrbios do sono e uma pontuação mais alta indicava uma má qualidade do sono. Foram classificados nove artigos com nível de evidência IV e um como nível III-2. Oito estudos apresentaram um risco de viés "crítico" $e$ dois em "moderado". Os estudos investigaram diferentes populações e descreveram os resultados como uma má qualidade do sono, considerando o IQSP, sendo os titulares de quarentena e profissionais de saúde como os mais comprometidos. Foi encontrado uma má qualidade do sono nas populações avaliadas nas publicações selecionadas, provavelmente, devido ao COVID-19 contribuir como um fator de risco para saúde mental. Intervenções psicológicas devem ser feitas para minimizar as consequências através do apoio social e capital social.

Palavras-chave Sono, Autoavaliação, Isolamento social, COVID-19 


\section{Introduction}

In December 2019, an outbreak of novel coronavirus disease (COVID-19) originated in Wuhan city, China, rapidly spread over China and to many other countries ${ }^{1}$. The World Health Organization (WHO) officially recognized the COVID-19 as a public health emergency of international concern (PHEIC) and declared the outbreak of COVID-19 as a "pandemic",3.

With the pandemic, the number of suspected and confirmed individuals increased, as well as the workload, work pressure, and risk of infection of front-line clinical staff to fight the epidemic $^{4}$.

Actions such as quarantine, social distancing, and lockdown was adopted in different countries to reduce virus circulation, and consequently, the lifestyles of the populations were changed. Although the measures adopted have been fundamental to reduce the outbreak of the virus, they may have a high psychological cost that should be noted ${ }^{5}$. Such outbreaks have typically resulted in widespread fear, anxiety, and a variety of psychological problems. In consequence, the stigmatization of patients with the disease and their relations, of care workers, even of all residents in hardest-hit areas occurred ${ }^{6}$. In general, infectious disease epidemics affect not only the physical health of patients but also the psychological health and well-being of the uninfected population in quarantine ${ }^{7}$.

In this context, COVID-19 has become an aggressive agent that triggers negative psychological effects that can raise levels of anxiety, depression, and stress in individuals ${ }^{8}$. These negative emotions contribute to affect the quality of sleep, leading to sleep disorders. This demonstrates the need to prevent and reduce these complications through psychological support, using attitudes of social capital ${ }^{7}$.

Besides, sleep disorders have special attention in the field of public health, due to good sleep quality favors to better health and well-being. Moreover, it is a primordial biological process for mental and physical health ${ }^{9}$. Despite public awareness, there are levels of anxiety that affect sleep quality during epidemics, including periods of population quarantine or self-isolation and in specific occupation $\mathrm{s}^{10}$. Some non-pharmacological interventions during the hospitalization ${ }^{11}$, confinement $^{12}$, and post-COVID-19 infection have been suggested ${ }^{13}$.

Sleep is considered as a period of rest for the body and mind, during which volition and con- sciousness are in partial or complete abeyance and the bodily functions partially suspended. Sleep has also been described as a behavioral state marked by characteristic immobile posture and diminished but readily reversible sensitivity to the external stimuli ${ }^{14,15}$. Good sleep quality can promote rapid recovery of body function, relieve work fatigue, and maintain sufficient energy, physical strength, and a healthy mental state ${ }^{4}$. It is a relevant parameter in the assessment of overall health, and a relevant factor in determining the risk of cardiovascular diseases $(\mathrm{CVD})^{16}$.

An observational clinic study during COVID-19 infection in China concluded that in medical staff, the levels of anxiety, stress, and self-efficacy were related to sleep quality and social support ${ }^{17}$. It was also observed, that many patients hospitalized developed anxiety and sleep disturbances after isolation treatment ${ }^{18}$.

Because the disturbances in sleep during outbreak of infectious disease, this systematic review aims to evaluate the sleep quality in individuals during the COVID-19 pandemic by the Pittsburgh Sleep Quality Index (PSQI).

\section{Methodology}

\section{Research question, search and registration}

This systematic review aimed to answer the following question: Can the sleep quality be affected during the pandemic COVID-19? The PECO ( $\mathrm{P}=$ Population, $\mathrm{E}=$ Exposition, $\mathrm{C}=\mathrm{Com}$ parison, $\mathrm{O}=$ Outcomes) our major components of the research question ${ }^{19} . \mathrm{P}=$ general population; $\mathrm{E}=\mathrm{Quarantine} ; \mathrm{C}=$ People not exposed to quarantine; $\mathrm{O}=$ Negative impacts on sleep quality by PSQI.

The search performed using the electronic databanks PubMed, Embase, Web of Science, and PEDro; held on May $22^{\text {nd }}, 2020$. The key words "COVID-19* and sleep and human*", "randomized controlled trial or clinical trial" were used in the search to find publications related. Therefore, there are situations where it is not possible to conduct randomized clinical trials (for ethical, operational, or financial issues), observational studies are presented as a suitable alternative.

This systematic review was registered on the International Prospective Register of Ongoing Systematic Reviews (PROSPERO), and the detailed protocol can be accessed online ${ }^{20}$. 


\section{Study selection and data extraction}

Independently of the year, all publications found on the databases were exported to a file, and the duplicates were manually removed by the author. Afterward, four steps were considered in the review. Records were identified in the searched databases (Identification) and two reviewers (MESMO, JPF) individually evaluated the titles and abstracts, and exclusion of irrelevant studies was made considering in eligibility criteria (Screening). Appropriated full texts were analyzed for eligibility (Eligibility criteria), and all relevant studies were taking into consideration to be selected for the current systematic review. The no agreements were solved by a third reviewer (EMM). Gray literature was not considered in the current systematic review.

The same researchers made the data extraction (author and year), studied population, PSQI score, sleep quality and specific condition, subjects (sample size), demographics (country, age, gender), a tool of the evaluation were extracted.

\section{Eligibility criteria}

The studies included in this review should (i) investigate the effects of the COVID-19 in the sleep quality of infected or no infected individuals through the PSQI; (ii) be written in English; (iii) to be cross-sectional design, control case, and cohort studies. Articles were excluded if they were duplicates, comments, letters, conference abstracts, books, book chapters, incomplete, systematic reviews, and meta-analysis, or narrative reviews. Also, articles that did not address sleep quality or did not specifically report the findings of COVID-19 were rejected. The publications involving other diseases and comorbidities in the quality of sleep were also withdrawn.

\section{PSQI and outcomes}

The PSQI allows evaluating the quality and disturbances of sleep over one month. The questionnaire consists of 19 self-assessed questions that are categorized into 7 components: 1) sleep quality, 2) sleep latency, 3) sleep duration, 4) sleep efficiency, 5) sleep disorders, 6) medication use to sleep, and 7) daytime sleepiness. Each component is classified in a score ranging from 0 to 3 . The sum of the scores for these 7 components produces a score ranging from 0 to 21 . It presents a cutoff point where it considers good sleep quality if PSQI $\leq 5$ and poor sleep quality if PSQI $>5^{21}$.

\section{Level of evidence (LE)}

The LE of each work was classified according to the National Health and Medical Research Council (NHMRC) 2003-2009 and the hierarchy of evidence ${ }^{22}$ were used to classify the included studies in this systematic review, which consists of six levels: I) LE I - Systematic review; II) LE II - Randomized controlled trial; III) LE III1 - Pseudo-randomized controlled trial; IV) LE III-2 - Comparative study with concurrent controls: non-randomized experimental trial, cohort study, case-control study, interrupted time series without a parallel control group; V) LE III-3 Comparative study without concurrent controls: historical control, two or more single-arm study, interrupted time series without a parallel control group; VI) LE IV - Cases series with either posttest or pre-test/post-test outcomes.

\section{Risk of bias of the selected studies}

The evaluation of the risk of bias of the included studies was using the A Cochrane Risk of Bias Assessment Tool for Non-randomized Studies (ACROBAT-NRSI) instrument, which compares the health effects of interventions. ACROBAT-NRSI covers seven domains divided into pre-intervention and post-intervention, at intervention and post-intervention. Each item was classified as the low, moderate, serious, or critical risk of bias and is needed to inform when no information is present ${ }^{23}$.

\section{Data analysis}

Considering the different study designs with several populations and the number of individuals that were in other specific conditions due to the COVID-19 pandemic, and eight publications were "poor", a metanalysis was not performed. Moreover, the study summarized the findings as a systematic review.

\section{Results}

Figure 1 shows a PRISMA flowchart ${ }^{19}$ with the different steps of the current systematic review, showing the number of articles selected, as well as the entire search process. Two hundred and eight papers were found from the databases and 


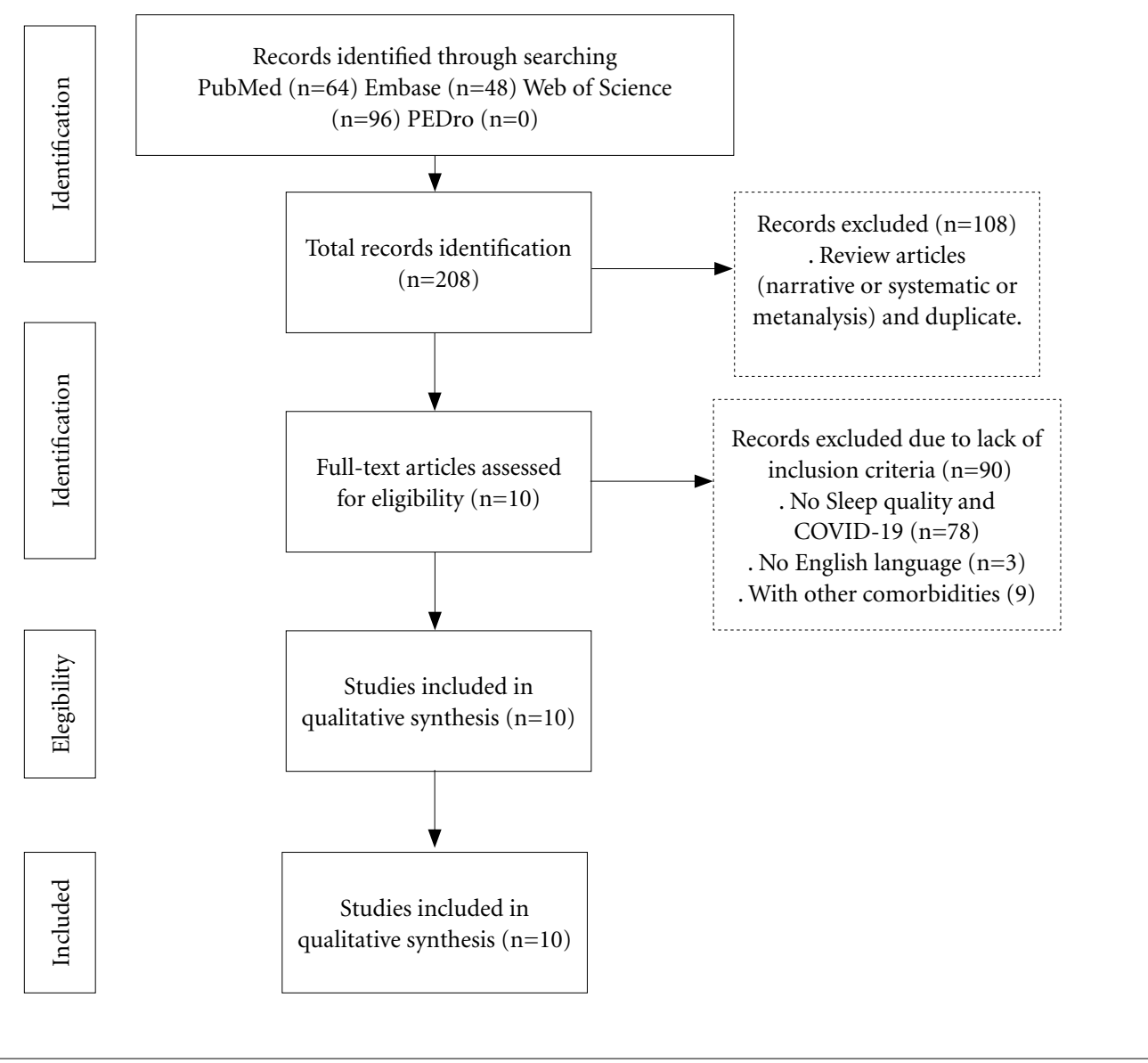

Figure 1. PRISMA flowchart of bibliographic research and its different stages of the process.

a hundred and eight were deleted because they were reviews (narrative or systematic or metanalysis) and duplicate. Considering the eligibility criteria were included only cross-sectionals studies. Of a hundred papers, ninety were excluded because they do not address sleep quality or do not specifically report findings of Coronavirus (COVID-19), as well as incomplete articles, with other comorbidities, conference summary, or in a language different from the English, remaining ten papers reached all the criteria to be included in this qualitative study. In the end, a total of ten articles resulted in that met all the criteria to be included in this qualitative study.

Considering the LE, Table 1 shows one study classified as Level III- $2^{4}$ and nine classified as a Lever IV (NHMRC) ${ }^{5,7,10,17,24-28}$, without interventions in the investigations.

Regarding risk of bias according ACROBAT-NRSI instrument A Cochrane Risk of Bias
Assessment Tool for Non-randomized Studies, eight selected publications have a "serious risk" of bias ${ }^{5,7,17,24-28}$, but only two publications in the "moderate risk" of bias ${ }^{4,10}$.

Table 2 indicates the characteristics of the populations of the selected publications. Most of the populations were from China and two were from Italy. A total of 13,025 individuals participated in the studies and 7,903 were females, 5,119 males, and 3 others not identified ${ }^{5}$. The ages ranged from 18 to over 60 years old. The questionnaire PSQI was used in all the publications.

Table 3 shows the results in PSQI according to the selected population involved and presented the sleep disturbance score. Considering the specifications of the studied populations, four publications were about individuals at front-line medical staff ${ }^{4}$, medical staff ${ }^{17}$, front-line pediatric healthcare works ${ }^{26}$, and front-line healthcare workers on many levels of traumatic exposure ${ }^{27}$. 
Table 1. ACROBAT-NRSI risk of bias and level of evidence of the selected publications.

\begin{tabular}{|c|c|c|c|c|c|c|c|c|c|}
\hline \multirow{2}{*}{ Authors/Year } & \multicolumn{8}{|c|}{ Items* } & \multirow{2}{*}{$\mathrm{LE}^{\star x}$} \\
\hline & $(1)$ & $(2)$ & (3) & $(4)$ & $(5)$ & $(6)$ & $(7)$ & $(8)$ & \\
\hline 1. Cellini et al. $(2020)^{24}$ & moderate & moderate & low & moderate & moderate & low & low & serious & IV \\
\hline 2. Wu and Wei $(2020)^{4}$ & moderate & moderate & low & moderate & low & low & low & moderate & III-2 \\
\hline 3. Huang and Zhao $(2020)^{25}$ & moderate & moderate & low & moderate & moderate & low & low & serious & IV \\
\hline 4. Yuan et al. $(2020)^{10}$ & moderate & low & low & moderate & low & low & low & moderate & IV \\
\hline 5. Xiao et al. $(2020)^{7}$ & moderate & moderate & low & moderate & moderate & low & low & serious & IV \\
\hline 6. Xiao et al. $(2020)^{17}$ & moderate & moderate & low & moderate & moderate & low & low & serious & IV \\
\hline 7. Casagrande et al. $(2020)^{5}$ & moderate & moderate & low & moderate & moderate & low & low & serious & IV \\
\hline 8. Wang et al. $(2020)^{26}$ & moderate & moderate & low & moderate & moderate & low & low & serious & IV \\
\hline 9. Yin et al. $(2020)^{27}$ & moderate & moderate & low & moderate & moderate & low & low & serious & IV \\
\hline 10. Liu et al. $(2020)^{28}$ & moderate & moderate & low & moderate & moderate & low & low & serious & IV \\
\hline
\end{tabular}

*Items: (1) Bias Due to Confounding; (2) Bias in Selection of Participants; (3) Bias in Measurement of Interventions; (4) Bias Due to Departures from Intended Interventions; (5) Bias Due to Missing Data; (6) Bias in Measurement of Outcomes; (7) Bias in Selection of Reported Results; (8) Overall RoB Judgment. ${ }^{*}$ LE - level of evidence according National Health and Medical Research Council (NHMRC).

Six publication were about individuals in quarantine during coronavirus outbreak ${ }^{25}$, individuals from Hubei province and non-endemic provinces in China $^{10}$, individuals non-hospitalized Italian resident $\mathrm{s}^{24}$, individual self-isolated at home in China during virus epidemic ${ }^{7}$, individuals residents in Wuhan and surrounding cities during coronavirus outbreak ${ }^{28}$ and individuals from different Italian territorial areas involved in the emergency during coronavirus outbreak (North, Centre, South) ${ }^{5}$. In all studies, sleep quality was poor in various populations.

\section{Discussion}

The purpose of this current systematic review was to collect data on the effects of the COVID-19 pandemic on sleep quality in individuals, summarizing the results obtained by the PSQI. This might aid to better understand the effect of the COVID-19 in the evaluated population. Only cross-sectional studies were included because no publications involving cohort and case-control were found. It is relevant to consider that only one study was classified as Level of evidence of III-2 and the other nine, as IV (NHMRC) due to the studies were performed without specific intervention. Furthermore, most of the selected works presented a serious risk of bias (ACROBAT-NRSI) (Table 1), considering the design of the studies and poor quality associated.

The rapid spread of the COVID-19 determines actions that can contribute to promoting psychological disturbance ${ }^{29}$. Moreover, individ- uals suffering from psychological problems are particularly vulnerable to the virus and the pandemic: vulnerabilities associated with medical comorbidities, illness, cognitive problems, health problems, and problems related to confinement and psychosocial complications. Furthermore, currently, most individuals are exposed to an unprecedented stressful situation of unknown duration. This can not only increase levels of stress during the day, anxiety, and depression, but also disrupt sleep ${ }^{30}$. Sleep questionnaires detailing pertinent sleep-related information and sleep logs are relevant and often useful. The PSQI assesses sleep quality and disturbances over one month $^{21}$.

The selected studies (Table 2 and Table 3 ) were conducted using an anonymous self-reported questionnaire PSQI, asking respondents, through the online system (digital media), for information on sleep quality during the endemic period. For this, several digital media activities were accessed for data collection, using internet browsing by computer or mobile phone $e^{4,5,10,26,28}$ on social networking sites, e-mail ${ }^{27}$, instant messaging, webchats ${ }^{25}$, video calls ${ }^{24}$.

Sleep quality is a key indicator of health. Most sleep disorders can be diagnosed by a comprehensive sleep history, which includes a detailed account of routine sleep-related habits. Sleepwake rhythms have changed markedly, with people going to bed and waking up later, and spending more time in bed, but, paradoxically, also reporting less sleep qualit $y^{24}$. Sleep disorders encompass a wide range of conditions that have been most recently categorized in the Interna- 
Table 2. Individuals characteristics of the selected studies about population size, country, age, gender, and tool of evaluation.

\begin{tabular}{|c|c|c|c|c|}
\hline Authors/Year & $\begin{array}{c}\text { Population size/ } \\
\text { Country }\end{array}$ & $\begin{array}{c}\text { Age }\left(M_{\text {age }} \pm S D\right) \\
\text { or year }\end{array}$ & $\begin{array}{c}\text { Gender (Male/ } \\
\text { Female) }\end{array}$ & $\begin{array}{c}\text { Tool for Evaluation } \\
\text { (sleep quality) }\end{array}$ \\
\hline Cellini et al. $(2020)^{24}$ & 1310 (Italy) & $23.9 \pm 3.6$ & $430 / 880$ & PSQI $^{(b)}$ (Italy version) \\
\hline Wu and Wei $(2020)^{4}$ & 120 (China) & $33.5 \pm 12.4$ & $31 / 89$ & PSQI $^{(\mathrm{c})}$ (China version) \\
\hline Huang and Zhao $(2020)^{25}$ & 7236 (China) & $35.3 \pm 5.6$ & $3284 / 3952$ & PSQI $^{(\mathrm{c})}$ (China version) \\
\hline Yuan et al. $(2020)^{10}$ & 939 (China) & $\begin{array}{c}\text { from } 18 \text { to } 60 \text { years or } \\
\text { greater }\end{array}$ & $357 / 582$ & $\mathrm{PSQI}^{(\mathrm{e})}$ \\
\hline Xiao et al. $(2020)^{7}$ & 170 (China) & $37.8 \pm 4.1$ & $101 / 69$ & PSQI \\
\hline Xiao et al. $(2020)^{17}$ & 180 (China) & $32.3 \pm 4.8$ & $51 / 129$ & PSQI (China version) \\
\hline Casagrande et al. $(2020)^{5}$ & 2291 (Italy) & $30.0 \pm 11.5$ & $580 / 1708^{(a)}$ & PSQI $^{(\mathrm{b})}$ \\
\hline Wang et al. $(2020)^{26}$ & 123 (China) & $33.7 \pm 8.4$ & $12 / 111$ & PSQI (China version) \\
\hline Yin et al. $(2020)^{27}$ & 371 (China) & $35.3 \pm 9.5$ & $143 / 228$ & PSQI $^{(\mathrm{d})}$ (China version) \\
\hline Liu et al. $(2020)^{28}$ & 285 (China) & $>18$ years & $130 / 155$ & $\begin{array}{c}\text { PSQI }^{(\mathrm{c}),(\mathrm{d})}(\text { China } \\
\text { version })\end{array}$ \\
\hline
\end{tabular}

Note: PSQI - Pittsburgh Sleep Quality Index; $\mathrm{M}_{\text {age }}$ - Average age; SD - standard deviation. ${ }^{(\mathrm{a})}$ Other not identified (03); ${ }^{(\mathrm{b})}$ Global

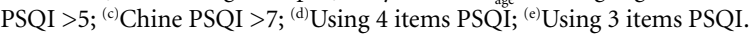

Table 3. Sleep quality of the evaluated populations.

\begin{tabular}{|c|c|c|c|c|}
\hline Authors/Year & Studied population & $\begin{array}{c}\text { M } \pm \text { SD PSQI } \\
\text { Score or } \mathbf{n}(\%)\end{array}$ & $\begin{array}{c}\text { Sleep } \\
\text { quality }\end{array}$ & Specific condition \\
\hline Cellini et al. $(2020)^{24}$ & $\begin{array}{l}\text { Individuals Non- } \\
\text { hospitalized }\end{array}$ & $686(52.4)$ & poor & Residents in lockdown \\
\hline Wu and Wei $(2020)^{4}$ & Front-line medical staff & $16.07 \pm 3.76^{\star}$ & poor & $\begin{array}{l}\text { Designated and non-designated } \\
\text { hospital with infection }\end{array}$ \\
\hline Huang and Zhao $(2020)^{25}$ & $\begin{array}{l}\text { Individuals with } \\
\text { different occupation }\end{array}$ & $1.317(18.2)^{*}$ & poor & During the COVID-19 outbreak \\
\hline Yuan et al. $(2020)^{10}$ & $\begin{array}{l}\text { Individuals with } \\
\text { different occupation }\end{array}$ & $192(36.4)$ & poor & $\begin{array}{l}\text { In endemic and non-endemic } \\
\text { provinces }\end{array}$ \\
\hline Xiao et al. $(2020)^{7}$ & $\begin{array}{l}\text { Individuals self-isolated } \\
\text { at home }\end{array}$ & $8.482 \pm 4.65^{\star}$ & poor & During the COVID-19 outbreak \\
\hline Xiao et al. $(2020)^{17}$ & Medical staff & $8.58 \pm 4.57^{\star}$ & poor & $\begin{array}{l}\text { Treating patients with } \\
\text { COVID-19 }\end{array}$ \\
\hline Casagrande et al. $(2020)^{5}$ & Individuals self-isolated & $5.69 \pm 3.40^{\star *}$ & poor & In three different areas in Italy \\
\hline Wang et al. $(2020)^{26}$ & $\begin{array}{l}\text { Front-line healthcare } \\
\text { workers }\end{array}$ & $9.87 \pm 1.98^{\star}$ & poor & At healthcare hospital \\
\hline Yin et al. $(2020)^{27}$ & $\begin{array}{l}\text { Front-line healthcare } \\
\text { workers }\end{array}$ & 10.60 & poor & $\begin{array}{l}\text { In different provinces of } \\
\text { China }\end{array}$ \\
\hline Liu et al. $(2020)^{28}$ & Individuals self-isolated & $59(20.7)$ & poor & During the COVID-19 outbreak \\
\hline
\end{tabular}

tional Classification of Sleep Disorders, Second Edition (ICSD-2) ${ }^{31}$.

These findings supply valuable information for policymakers and mental health professionals worldwide regarding the psychological impact of an infectious disease outbreak. Normative and systematic assessments and observation are conducted with a view to early strengthening, underpin, and providing reference basis in strategies for improving sleep quality ${ }^{32}$. Psychological first aids could be delivered by someone who understands the basic principles, training community 
volunteers in the future might be an effective and sustainable way to alleviate the mental stress of the general public during times of $\mathrm{crisis}^{33}$.

As it was shown in Table 3, the quality of sleep of the various evaluated populations related to the COVID-19 was poor. A study showed that sleep deficient humans and rodents exhibit a proinflammatory component; therefore, sleep loss is considered as a risk factor for developing cardiovascular, metabolic, and neurodegenerative diseases (e.g., diabetes, Alzheimer's disease, and multiple sclerosis $)^{34}$. And recurring longterm episodes of insufficient sleep can lead to emotional reactions with negative repercussions for the body, such as fatigue, palpitation, chest tightness, drowsiness, irritability, inattention, headache, decrease appetite and dizziness, in addition to increasing barriers to various systems, such as immunity, learning, and memory ${ }^{4}$. Evidence indicated that mental health problems could occur in healthcare professionals and survivors during the COVID-19 pandemic ${ }^{35}$ and this might justify our findings of the quality of the sleep.

Moreover, individuals with depression are prone to persistent sleep disorders, which are manifested as insomnia, difficulty falling asleep, early waking, sleep rhythm disorder, and other forms. It was associated with sleep disturbance in health workers ${ }^{36}$. These characteristics have been concluded in studies by $\mathrm{Wu}$ and $\mathrm{Wei}^{4}$, Xiao et al. ${ }^{17}$, Wang et al. ${ }^{26}$ and Yin et al..$^{27}$, when healthcare teams who treated patients in front-line with high exposure to COVID-19, showed more sleep disorders and higher latency, indicating worse sleep quality than those with less exposure, especially when they feel their life is in danger.

Besides, previous studies have shown that the survivors who participated in the Severe Acute Respiratory Syndrome (SARS) epidemic ${ }^{37}$, Middle East Respiratory Syndrome (MERS) epidem$\mathrm{ic}^{38}$ and influenza A (H1N1) ${ }^{39}$ had adverse neuropsychiatric impacts that persisted with this effect for a long time after the end of the epidemic, presenting the symptoms of anxiety, depression, stress and post-stress traumatic disorder ${ }^{37,40,41}$. A higher prevalence of these symptoms is associated with worse subjective quality of sleep and a fragmented sleep pattern ${ }^{28}$. In the current study, the COVID-19 pandemic was responsible for similar levels of alteration of the quality of sleep.

Some emergency management measures are suggested that should be taken to improve the quality of sleep in front-line healthcare workers during a pandemic: strengthen exercise interven- tion, psychological counseling, drug intervention treatment strategies if necessary ${ }^{4}$, provide individually targeted interventions of mental health services $^{17,26}$, establish a shift system to allow to take turns to rest and a hotline to provide guidance by phone $e^{27}$. For confined individuals, are suggested to: provide public awareness, psychosocial support interventions to improve social isolation $^{24}$, provide online health education to reduce uncertainty and panic ${ }^{7}$, effective mental health services ${ }^{28}$, psychological intervention ${ }^{5}$, avoid receiving too many harmful rumors, maintain exercise regularly ${ }^{10,25}$ and for patients in isolated treatment, progressive muscle relaxation is suggested as an auxiliary method ${ }^{18}$.

This systematic review is, to the best of our knowledge, the first that evaluates the effect of quarantine during COVID-19 pandemic in sleep quality. Moreover, the findings of this systematic review might permit to establish actions to aid the populations exposed to the COVID-19 pandemic.

This work also has some limitations, such as (I) more representative need for research in other affected countries, particularly in a vulnerable population, since the results obtained was limited only to China and Italy; (II) some studies used the PSQI with a different cut-off point, depending on the version applied in your country or just assessed some items of the instrument; (III) exclusion of non-English language studies can have excluded some relevant information; (IV) some cross-sectional design with a small sample size difficult to make causal inferences; (V) there was a lack of follow-up studies to show changes in sleep disorders, as well as exposure, infection or attitudes of SARS-CoV-2(COVID-19) in individuals, were not measured; (VI) the measures of sleep quality used may be vulnerable because of its online self-reports; (VII) the data obtained was unbalanced in terms of sex, with more females than males.

\section{Conclusion}

Considering the PSQI, poor sleep quality was found in the populations evaluated in the selected publications, probably, due to the COVID-19 to contributes as a risk factor for disorders related to mental health. Moreover, the findings of this systematic review will be relevant to evaluate psychological interventions, focused on improving psychological well-being and reducing the risk of occurrence of disorders related to stress, de- 
pression, anxiety, and fatigue, in addition to mitigating the significant immediate and long-term effects on sleep quality, due to the undesirable consequences of the COVID-19. Furthermore, it is important to consider the need to carry out studies with a high level of evidence about the analyzed outcome.

\section{Collaborations}

LFF Souza: conceptualization, data curation and writing-original draft. LL Paineiras-Domingos: formal analysis and writing-review and editing. MES Melo-Oliveira: data curation and validation. J Pessanha-Freitas: software and visualization. E Moreira-Marconi: methodology and writing-review and editing. ACR Lacerda: methodology and writing-review and editing. VA Mendonça: methodology and writing-review and editing. DC Sá-Caputo: visualization and writing-review and editing. M Bernardo-Filho: investigation, supervision and writing-review and editing.

\section{Acknowledgments}

The authors gratefully acknowledge the support of the Coordenação de Aperfeiçoamento de Pessoal de Nível Superior (CAPES) (Finance Code - 001), Conselho Nacional de Desenvolvimento Científico e Tecnológico ( $\mathrm{CNPq})$, the Universidade do Estado do Rio de Janeiro (UERJ) and the Fundação de Amparo à pesquisa do Estado do Rio de Janeiro (FAPERJ). 


\section{References}

1. Munster VJ, Koopmans M, van Doremalen N, van Riel D, de Wit E. A novel coronavirus emerging in China - Key questions for impact assessment. N Engl J Med 2020; 382(8):692-694.

2. World Health Organization (WHO). Coronavirus Disease (COVID-19) Dashboard [Internet]. Geneva: WHO; 2020. Disponível em: https://covid19.who. int/?gclid=CjwKCAjwtNf6BRAwEiwAkt6UQiBc6w5D6BwdPiVE-vFZdv1MeCyVJ9tLl_pLUOdb4h9O00-A1NRTIhoC7W4QAvD_BwE

3. World Health Organization (WHO). Director-General's opening remarks at the media briefing on COVID-19. Geneva: WHO, 2020. Disponível em: https:// www.who.int/dg/speeches/detail/who-director-general-s-opening-remarks-at-the-media-briefing-on-covid-19---25-may-2020

4. Wu K, Wei X. Analysis of Psychological and Sleep Status and Exercise Rehabilitation of Front-Line Clinical Staff in the Fight Against COVID-19 in China. Med Sci Monit Basic Res 2020; 26:e924085.

5. Casagrande M, Favieri F, Tambelli R, Forte G. The enemy who sealed the world: effects quarantine due to the COVID-19 on sleep quality, anxiety, and psychological distress in the Italian population. Sleep Med 2020; 75:12-20.

6. Mak IWC, Chu CM, Pan PC, Yiu MGC, Ho SC, Chan VL. Risk factors for chronic post-traumatic stress disorder (PTSD) in SARS survivors. Gen Hosp Psychiatry 2010; 32(6):590-598.

7. Xiao H, Zhang Y, Kong D, Li S, Yang N. Social capital and sleep quality in individuals who self-isolated for 14 days during the coronavirus disease 2019 (COVID-19) outbreak in January 2020 in China. Med Sci Monit 2020; 26:e923921.

8. Ornell F, Schuch JB, Sordi AO, Kessler FHP. "Pandemic fear" and COVID-19: Mental health burden and strategies. Braz J Psychiatry 2020; 42(3):232-235.

9. Simões ND, Monteiro LHB, Lucchese R, De Amorim TA, Denardi TC, Vera I, Silva GC, Sverzut C. Quality and sleep duration among public health network users. ACTA Paul Enferm 2019; 32(5):530-537.

10. Yuan S, Liao Z, Huang H, Jiang B, Zhang X, Wang Y, Zhao M. Comparison of the indicators of psychological stress in the population of Hubei province and non-endemic provinces in China during two weeks during the coronavirus disease 2019 (COVID-19) outbreak in February 2020. Med Sci Monit 2020; 26:e923767

11. Sañudo B, Seixas A, Gloeckl R, Rittweger J, Rawer R, Taiar R, van der Zee EA, van Heuvelen MJG, Lacerda AC, Sartorio A, Bemben M, Cochrane D, Furness T, Sá-Caputo DC, Bernardo-Filho M. Potential application of whole-body vibration exercise for improving the clinical conditions of covid-19 infected individuals: A narrative review from the world association of vibration exercise experts (wavex) panel. Int J Environ Res Public Health 2020; 17(10):3650.

12. Sá-Caputo DC, Taiar R, Seixas A, Sanudo B, Sonza A Bernardo-Filho M. A Proposal of Physical Performance Tests Adapted as Home Workout Options during the COVID-19 Pandemic. Appl Sci 2020; 10(14):4755.
13. Li Z, Zheng C, Duan C, Zhang Y, Li Q, Dou Z, Li J, Xia $W$. Rehabilitation needs of the first cohort of post-acute COVID-19 patients in Hubei, China. Eur J Phys Rehabil Med 2020; 56(3):339-344.

14. The Free Dictionary by Farlex. Definition of sleep [Internet]. 2012. Disponível em: https://medical-dictionary.thefreedictionary.com/sleep

15. Doherty R, Madigan S, Warrington G, Ellis J. Sleep, and nutrition interactions: Implications for athletes. Nutrients 2019; 11(4):822.

16. Araujo PAB, Sties SW, Wittkopf PG, Schmitt Netto A, Gonzáles AI, Lima DP, Guimarães SN, Aranha EE, Andrade A, Carvalho T. Índice da qualidade do sono de Pittsburgh para uso na reabilitação cardiopulmonar e metabólica. Rev Bras Med Esporte 2015; 21(6):472475.

17. Xiao H, Zhang Y, Kong D, Li S, Yang N. The effects of social support on sleep quality of medical staff treating patients with coronavirus disease 2019 (COVID-19) in January and February 2020 in China. Med Sci Monit 2020; 26:e923549.

18. Liu K, Chen Y, Wu D, Lin R, Wang Z, Pan L. Effects of progressive muscle relaxation on anxiety and sleep quality in patients with COVID-19. Complement Ther Clin Pract 2020; 39:101132.

19. Liberati A, Altman DG, Tetzlaff J, Mulrow C, Gøtzsche PC, Ioannidis JPA, et al. The PRISMA statement for reporting systematic reviews and meta-analyses of studies that evaluate health care interventions: explanation and elaboration. J Clin Epidemiol 2009; 62(10):e1-e34.

20. Ferreira-Souza LF, Moreira-Marconi E, PaineirasDomingos LL, Sá-Caputo DC, Melo-Oliveira MES, Bernardo-Filho M, Pessanha-Freitas J, Lacerda AC, Mendonça VA. The impact of COVID-19 pandemic in the quality of sleep by Pittsburgh Sleep Quality Index: A systematic review [Internet]. National Institute for Health Research (NIHR). International prospective register of systematic reviews (PROSPERO). 2020. Disponível em: https://www.crd.york.ac.uk/prospero/ display_record.php?RecordID $=191235$

21. Buysse DJ, Reynolds CF, Monk TH, Berman SR, Kupfer DJ. The Pittsburgh sleeps quality index: A new instrument for psychiatric practice and research. Psychiatry Res 1989; 28(2):193-213.

22. Merlin T, Weston A, Tooher R. Extending an evidence hierarchy to include topics other than treatment: Revising the Australian "levels of evidence." BMC Med Res Methodol 2009; 9(1):34.

23. ACROBAT-NRSi (A Cochrane Risk of Bias Assessment Tool: for Non-Randomized Studies of Interventions) for non-clinical community-based studies: a participatory workshop using a worked example from public health [Internet]. Colloquium Abstracts. Disponível em: https://abstracts.cochrane.org/2015vienna/acrobat-nrsi-cochrane-risk-bias-assessmenttool-non-randomized-studies-interventions-non

24. Cellini N, Canale N, Mioni G, Costa S. Changes in sleep pattern, sense of time and digital media use during COVID-19 lockdown in Italy. J Sleep Res 2020; 29(4):e13074. 
25. Huang Y, Zhao N. Generalized anxiety disorder, depressive symptoms, and sleep quality during COVID-19 outbreak in China: a web-based cross-sectional survey. Psychiatry Res 2020; 288:112954.

26. Wang S, Xie L, Xu Y, Yu S, Yao B, Xiang D. Sleep disturbances among medical workers during the outbreak of COVID-2019. Occup Med 2020; 70(5):364-369.

27. Yin Q, Sun Z, Liu T, Ni X, Deng X, Jia Y, Shang Z, Zhou Y, Liu W. Posttraumatic stress symptoms of health care workers during the coronavirus disease 2019. Clin Psychol Psychother 2020; 27(3):384-395.

28. Liu N, Zhang F, Wei C, Jia Y, Shang Z, Sun L, Zhou Y, Wang Y, Liu W. Prevalence and predictors of PTSS during COVID-19 outbreak in China hardest-hit areas: Gender differences matter. Psychiatry Res 2020; 287:112921.

29. Castro-De-Araujo LFS, Machado DB. Impact of covid-19 on mental health in a low and middle-income country. Cien Saude Colet 2020; 25(Supl. 1):24572460.

30. Altena E, Baglioni C, Espie CA, Ellis J, Gavriloff D, Holzinger B, Schlarb A, Frase L, Jernelöv S, Riemann D. Dealing with sleep problems during home confinement due to the COVID-19 outbreak: Practical recommendations from a task force of the European CBT-I Academy. J Sleep Res 2020; 29(4):e13052.

31. Sateia MJ. International classification of sleep disorders-third edition highlights and modifications. Chest 2014; 146(5):1387-1394.

32. Qi J, Xu J, Li BZ, Huang JS, Yang Y, Zhang ZT, Yao DA, Liu QH, Jia M, Gong DK, Ni XH, Zhang QM, Shang FR, Xiong N, Zhu CL, Wang T, Zhang X. The evaluation of sleep disturbances for Chinese frontline medical workers under the outbreak of COVID-19. Sleep Med 2020; 72:1-4.

33. Huang Y, Zhao N. Mental health burden for the public affected by the COVID-19 outbreak in China: Who will be the high-risk group? Psychol Health Med 2021; 26(1):23-34.

34. Hurtado-Alvarado G, Pavón L, Castillo-García SA, Hernández ME, Domínguez-Salazar E, VelázquezMoctezuma J, Gómez-González B. Sleep Loss as a Factor to Induce Cellular and Molecular Inflammatory Variations. Clin Dev Immunol 2013; 2013:801341.

35. Huang Y, Zhao N. Chinese mental health burden during the COVID-19 pandemic. Asian J Psychiatr 2020; 51:102052.
36. Liu X, Kakade M, Fuller CJ, Fan B, Fang Y, Kong J, Guan Z, Wu P. Depression after exposure to stressful events: Lessons learned from the severe acute respiratory syndrome epidemic. Compr Psychiatry 2012; 53(1):15-23.

37. Wu KK, Chan SK, Ma TM. Posttraumatic stress after SARS. Emerg Infect Dis 2005; 11(8):1297-300.

38. Lee SM, Kang WS, Cho AR, Kim T, Park JK. The psychological impact of the 2015 MERS outbreak on hospital workers and quarantined hemodialysis patients. Compr Psychiatry 2018; 87:123-127.

39. Zhou H, Lu S, Chen J, Wei N, Wang D, Lyu H, Shi C, $\mathrm{Hu}$ S. The landscape of cognitive function in recovered COVID-19 patients. J Psychiatr Res 2020; 129:98102.

40. Wu KK, Chan SK, Ma TM. Posttraumatic stress, anxiety, and depression in survivors of the severe acute respiratory syndrome (SARS). J Trauma Stress 2005; 18(1):39-42.

41. Hawryluck L, Gold WL, Robinson S, Pogorski S, Galea S, Styra R. SARS control and psychological effects of quarantine, Toronto, Canada. Emerg Infect Dis 2004; 10(7):1206-1212.

Article submitted 25/07/2020

Approved 15/01/2021

Final version submitted 17/01/2021

Chief editors: Romeu Gomes, Antônio Augusto Moura da Silva 